\title{
Findings in an Elderly Patient after a Fall
}

\section{Qasem M. Aljabr, MD}

Diplomate, American Board of Family Medicine.

Fellow, Geriatric Medicine, University of Miami/Jackson Memorial Hospital, United States.

Family Medicine Trainer at Postgraduate Center of Family and Community Medicine,

Hofuf, Al Ahsa, Saudi Arabia

\section{Correspondence}

Dr. Qasem M. Aljabr

P.O. Box 2071, Al Hofuf 31982

Al Ahsa, Saudi Arabia

e.M: Dr.Qasem.Aljabr@gmail.com

Submission: 26 April 2017

Accepted: 03 May 2017

\section{Citation}

Aljabr QM. Findings in an elderly patient after a fall. JKAU Med Sci 2017; 24 (3): 51-54. DOI: 10.4197/Med. 24.3.5

\begin{abstract}
A 76-year-old male presented with neck pain beginning a month earlier, when he tripped over a ledge while exiting his truck. The patient landed on his face and lost consciousness. In the emergency room, the initial work up, including a head computed tomography scan, came back negative, but the fall work-up was incomplete. He was discharged with a physical therapy appointment to manage his neck pain but did not go. The patient's pain continued for another four weeks before he went to the clinic. The pain was located at the midline of his posterior cervical spine with limited range of motion. He was otherwise asymptomatic. A more comprehensive fall assessment and work-up was completed. An immediate neck computed tomography scan was ordered and revealed subacute Stage 2 odontoid fractures. The patient was placed in a neck collar. An urgent appointment with the neurosurgery clinic was requested. The neurosurgeon reviewed the neck computed tomography scan; a follow up by magnetic resonance imaging confirmed the findings. After discussing treatment options, the patient agreed to proceed with fusion surgery. This case demonstrates the importance of performing a complete fall assessment and workup to ensure early detection and prevention of serious or life-threatening injuries.
\end{abstract}

\section{Keywords}

Falls; Neck fracture; Stage 2 odontoid fractures

\section{Introduction}

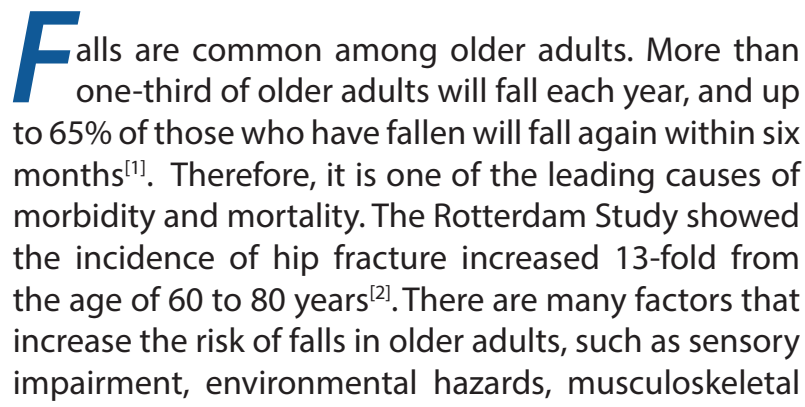

weakness, uncontrolled chronic diseases, and slower reflexes. As individuals age, these factors all affect a person's ability to walk and balance $\mathrm{e}^{[1,2]}$.

In the United States, falls and related injuries have a great impact on healthcare costs in the geriatric population. Many articles have shown the overwhelming cost-burden of falls in healthcare spending. One analysis of healthcare costs related to falls in 2012 demonstrated a cost of up to $\$ 30,000$ per fall requiring hospitalization ${ }^{[3]}$. 
Even among patients who do not have a physical injury, falls are associated with subsequent functional decline, higher rates of nursing-home admissions, and increased use of medical services. Although fall-related deaths are uncommon, fall-related complications are the leading cause of death from injury in adults $\geq 65$ years old ${ }^{[4]}$ :

\section{Case Description}

A 76-year-old white male presented at the clinic as a walk-in patient complaining of neck pain lasting for one month. The pain started when he fell while exiting his truck. The patient landed on his face, lost consciousness for a few minutes, and a few hours later his wife accompanied him to the emergency room (ER) for further evaluation and assessment.

An initial fall work up came back negative, including head computed tomography (CT) scan that cleared him of any acute findings. However, no further imaging study was done to evaluate his neck pain. The patient was discharged from the ER with an appointment for physical therapy to manage his neck pain, but the patient decided not to attend the session.

After one month of neck pain and stiffness without seeking any further medical advice or rescheduling his physical therapy appointment, he came to the geriatric clinic as a walk-in patient. A detailed history has been obtained from the patient regarding the circumstances of the fall and he denies any history of dizziness, imbalance, impaired mobility, frequent falls or memory difficulties. The patient independently performs daily life activities. Syncope and seizure have been excluded, but he reported dysphagia with liquids and foods since the fall.

In the physical exam, a comprehensive geriatric assessment was performed, including orthostatic vitals, a brief cognitive assessment, cardiovascular exam, and a neurological exam, which were all normal. The musculoskeletal exam revealed mild tenderness to palpation in the posterior midline of the cervical spine and limited range of motion, muscle groups with normal motor power, sensations were preserved and the plantar response was extensor bilaterally.

A CT scan of the patient's neck was immediately ordered and revealed subacute Stage 2 odontoid fractures (Fig. 1). The neck collar was placed and an urgent appointment with the neurosurgery clinic was

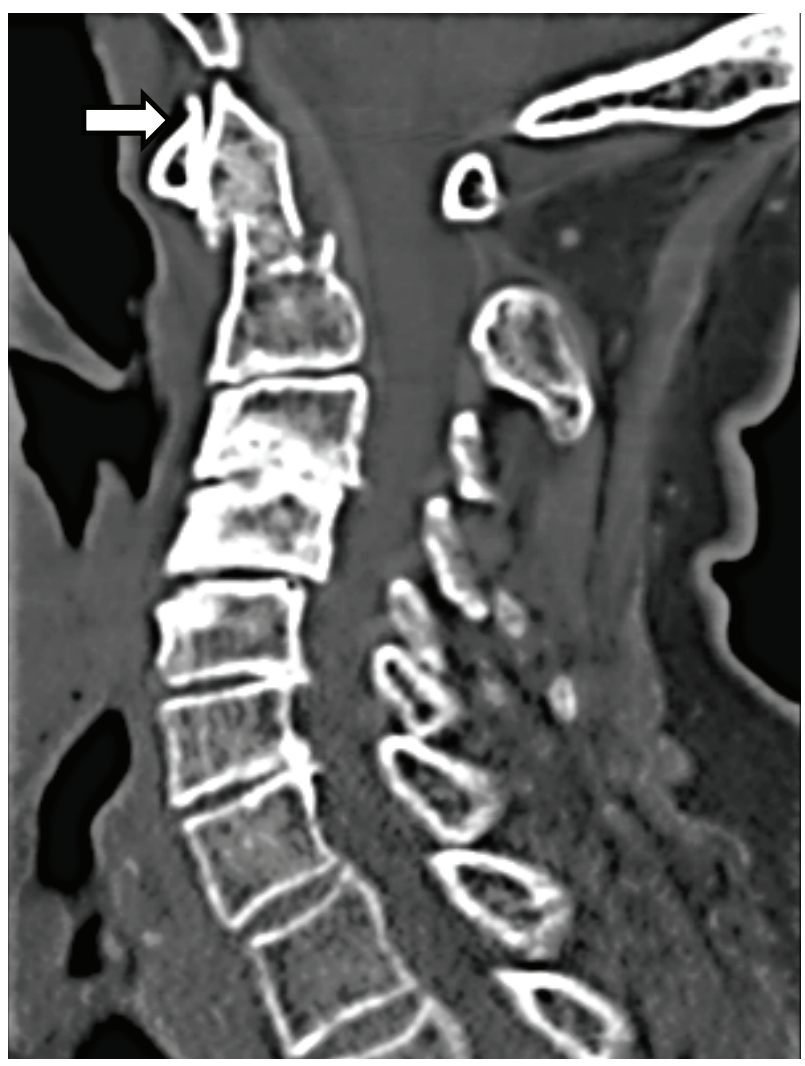

Figure 1. Cervical spine CT scan shows stage 2 subacute odontoid fracture (arrow).

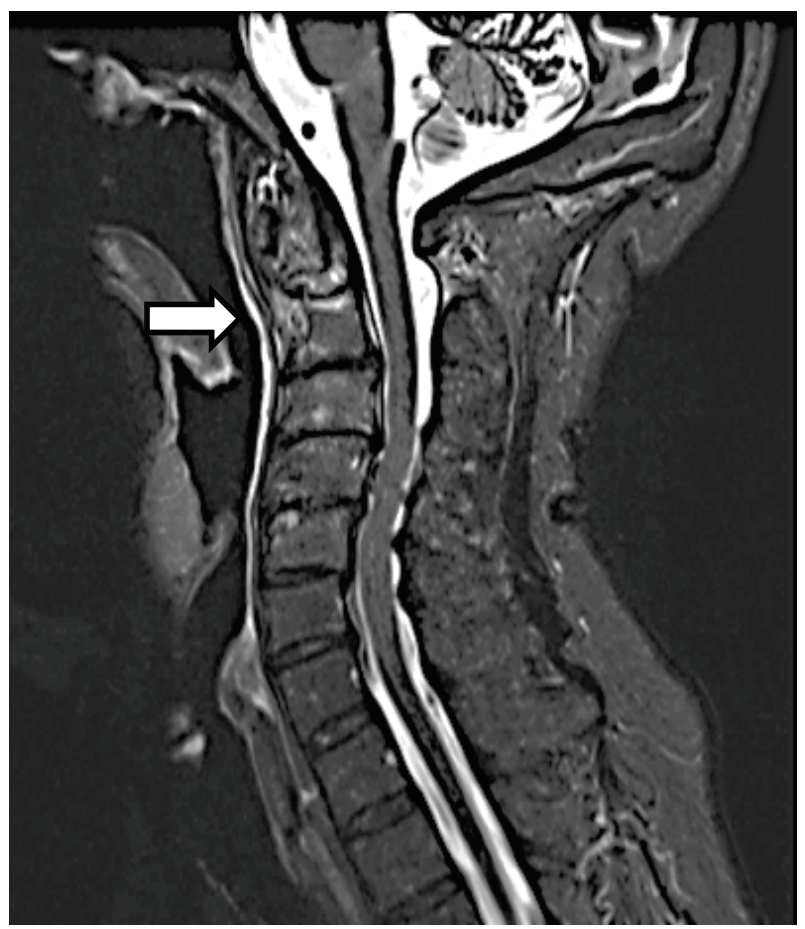

Figure 2. Cervical spine MRI confirms stage 2 subacute odontoid fracture without spinal cord injury (arrow). 
requested. The neurosurgeon reviewed the neck CT scan; a follow up magnetic resonance imaging (MRI) confirmed the findings and ruled out any spinal cord injury (Fig. 2). After discussing treatment options with the patient, he agreed to proceed with fusion surgery.

\section{Discussion}

Falls are one of the leading causes of morbidity and mortality among older adults, around $40 \%$ of patients above age 65 will fall each year and two-thirds of those patients who fall will fall again within six months ${ }^{[1]}$. Therefore, screening older adults for falls and fall risk factors is highly recommended.

In this patient, the consequences could have been spinal cord injury because degenerative changes caused by aging make vertebra $\mathrm{C} 4-\mathrm{C} 7$ stiffer. As a result, the $\mathrm{C} 1-\mathrm{C} 2$ segment becomes the most mobile portion of the cervical spine, and the damage may lead to quadriplegia with respiratory center involvement due to spinal cord compression ${ }^{[5]}$.

Cervical spine fracture can be life threatening and has a higher mortality rate in patients more than 65 years old ${ }^{[5,6]}$. Therefore, a neck CT scan should be considered in cervical spine trauma patients with changes in mental status or neck pain ${ }^{[5-8]}$. In cases of older adults with falls, a detailed history, careful physical examination and screening for fall-related injuries are needed. Although there is no routine work up for fall injuries, they should be directed based on history and findings from a physical exam ${ }^{[6]}$.

Considering the healthcare burden of falls and fallrelated injuries, it is important to control risk factors associated with falls to prevent unfavorable outcomes and costs. Many interventions and preventative measures have been studied and are effective, including a multifactorial risk assessment and management program, exercise, environmental modification, and education $^{[8,9]}$.

\section{Conclusion}

Falls are a common geriatric syndrome; they can lead to serious injuries in older adults and affect them physically and financially. Given the impact of falls on patients' quality of life, complete fall assessment and early intervention are needed to prevent unfavorable outcomes.

\section{Conflict of Interest}

The author has no conflict of interest.

\section{Disclosure}

The author did not receive any commercial or financial support for this study. The author has no financial interest in any of the products, devices, or drugs mentioned in this article.

\section{Ethical Approval}

Obtained.

\section{References}

[1] Chang HJ, Lynm C, Glass RM. JAMA patient page. Falls and older adults. JAMA 2010; 303(3): 288.

[2] Aspray TJ, Stevenson P, Abdy SE, Rawlings DJ, Holland T, Francis RM. Low bone mineral density measurements in care home residents-a treatable cause of fractures. Age Ageing 2006; 35(1): 37-41.

[3] Burns ER, Stevens JA, Lee R. The direct costs of fatal and non-fatal falls among older adults-United States. J Safety Res 2016; 58: 99-103.

[4] Kannus $P$, Sievänen $H$, Palvanen $M$, Järvinen $T$, Parkkari $J$. Prevention of falls and consequent injuries in elderly people. Lancet 2005; 366(9500): 1885-1893.

[5] Malik SA, Murphy M, Connolly P, O'Byrne J. Evaluation of morbidity, mortality and outcome following cervical spine injuries in elderly patients. Eur Spine J 2008; 17(4): 585-591.

[6] Fassett DR, Harrop JS, Maltenfort M, Jeyamohan SB, Ratliff JD, Anderson DG, Hilibrand AS, Albert TJ, Vaccaro AR, Sharan AD. Mortality rates in geriatric patients with spinal cord injuries. J Neurosurg Spine 2007; 7(3): 277-281.

[7] Como JJ, Leukhardt WH, Anderson JS, Wilczewski PA, Samia $\mathrm{H}$, Claridge JA. Computed tomography alone may clear the cervical spine in obtunded blunt trauma patients: a prospective evaluation of a revised protocol. J Trauma 2011; 70(2): 345-349.

[8] Duane TM, Scarcella N, Cross J, Wolfe LG, Mayglothling J, Aboutanos MB, Whelan JF, Malhotra AK, Ivatury RR. Do flexion extension plain films facilitate treatment after trauma? Am Surg 2010; 76(12): 1351-1354.

[9] Chang JT, Morton SC, Rubenstein LZ, Mojica WA, Maglione M, Suttorp MJ, Roth EA, Shekelle PG. Interventions for the prevention of falls in older adults: systematic review and meta-analysis of randomized control trials. BMJ 2004; 328(7411): 680 


$$
\begin{aligned}
& \text { حاصل على البورد الأمريكي في طب الاسرة }
\end{aligned}
$$

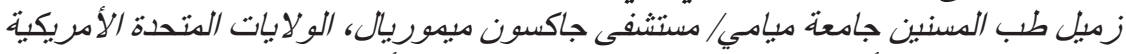

$$
\begin{aligned}
& \text { مدرب زمالة طب الأسرة في مركز الدراسات العليا لطب الأسرة والمجتمع الهفوف، الاحساء، الدملكة العربية السعودية }
\end{aligned}
$$

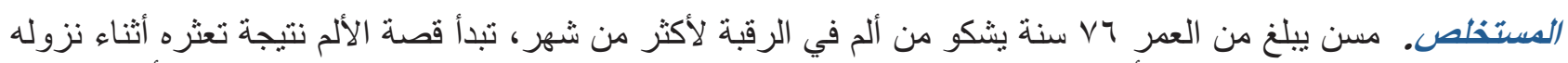

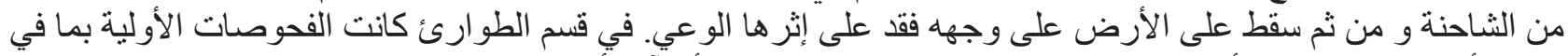

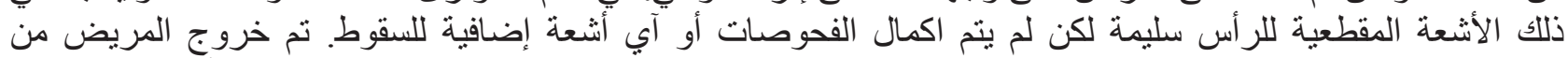

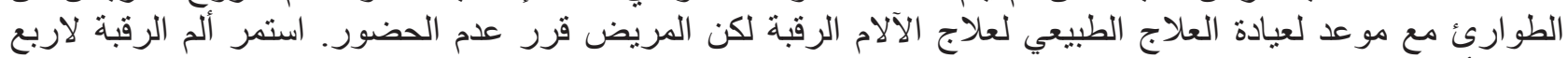

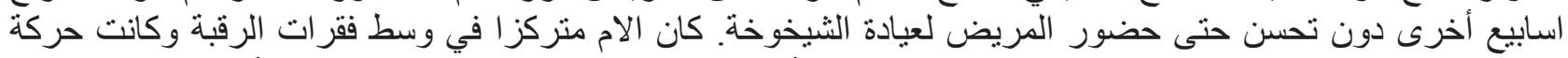

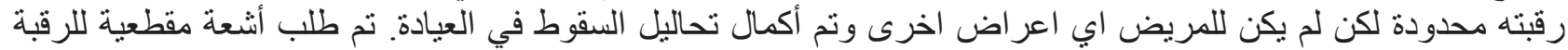

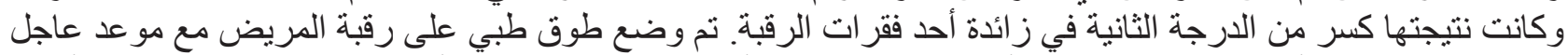

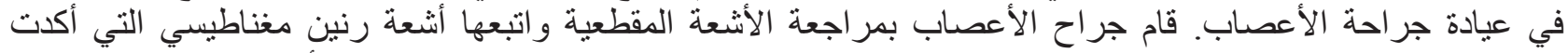

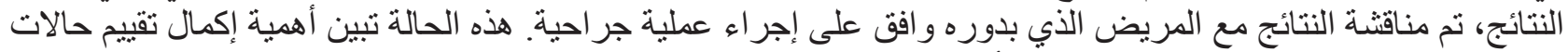

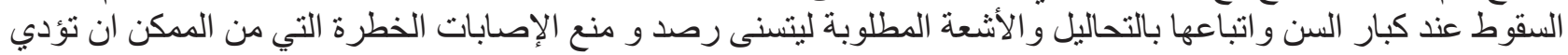

